ICTD Working Paper 123

\section{There and Back Again: The Making of Uganda's Mobile Money Tax}

Adrienne Lees and Doris Akol

July 2021 
There and Back Again: The Making of Uganda's Mobile Money Tax

Adrienne Lees and Doris Akol

ICTD Working Paper 123

First published by the Institute of Development Studies in July 2021

(C) Institute of Development Studies 2021

ISBN: [978-1-78118-825-5]

DOI: $10.19088 /$ ICTD. 2021.012

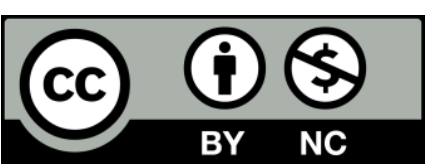

This is an Open Access paper distributed under the terms of the Creative Commons Attribution Non Commercial 4.0 International license, which permits downloading and sharing provided the original authors and source are credited - but the work is not used for commercial purposes. http://creativecommons.org/licenses/by-nc/4.0/legalcode

\section{Available from:}

The International Centre for Tax and Development at the Institute of Development Studies, Brighton BN1 9RE, UK

Tel: +44 (0) 1273606261

Email: info@ictd.ac

Web: www.ictd.ac/publication

Twitter: @ICTDTax

Facebook: www.facebook.com/ICTDtax

IDS is a charitable company limited by guarantee and registered in England

Charity Registration Number 306371

Charitable Company Number 877338 


\title{
There and Back Again: The Making of Uganda's Mobile Money Tax
}

\author{
Adrienne Lees and Doris Akol
}

\section{Summary}

This paper evaluates the appropriateness of the tax policymaking process that led to the introduction, and the later adaptation, of a tax on mobile money transactions in Uganda in 2018. We examine the unusual source of the proposal, how this particular tax diverged from the usual tax policymaking process, and whether certain key stakeholders were excluded. We argue that weaknesses in the tax policymaking process undermined the quality of policy design, and resulted in a period of costly, and avoidable, policy adjustment. This case study is relevant for Uganda as well as for other low-income countries which could be exposed to similar challenges in designing effective taxes for the mobile money industry.

Keywords: mobile money; taxation; policymaking process.

Adrienne Lees is a Research Officer at the International Centre for Tax and Development, at the Institute of Development Studies. From 2017 to 2019, she was an ODI Fellow in the Tax Policy Department of the Ministry of Finance, Planning and Economic Development in Uganda. During her Fellowship, Adrienne was closely involved in researching, developing, and drafting Uganda's first Domestic Revenue Mobilisation Strategy.

Doris Akol is a Senior Policy and Engagement Advisor for the DIGITAX programme at the International Centre for Tax and Development. She has over 20 years of experience in taxation policy and administration and has held various positions in the Uganda Revenue Authority. Most recently, until March 2020, she was the Commissioner General and a member of the Board of Directors. Doris was also a member of the Council of the African Tax Administrators' Forum (ATAF) from 2014 to 2020. 


\section{Contents}

Summary 3

Acknowledgements $\quad 6$

Acronyms 6

$\begin{array}{ll}\text { Introduction } & 7\end{array}$

$1 \quad$ Study context and methodology 10

1.1 The importance of mobile money in Uganda 10

1.2 Methodology 11

$2 \quad$ The Ugandan tax policymaking process 11

$2.1 \quad$ The planning phase 13

2.2 The developmental phase 13

2.3 The approval phase 13

2.4 The legislative phase 14

$\begin{array}{ll}2.5 & \text { The implementation phase } \\ \end{array}$

$3 \quad$ The approach to the mobile money tax 14

3.1 Planning phase: the budgetary background 14

3.2 Developmental phase 15

3.2.1 Policy initiation and motivation $\quad 15$

3.2.2 The response from the MFPED 17

3.3 Legislative phase: Parliamentary process and debate 18

3.4 Implementation phase 20

3.4.1 Public response 20

3.4.2 The amendment process 20

$\begin{array}{lll}3.5 & \text { Revenue performance } & 21\end{array}$

$4 \quad$ Where did the tax policymaking process fail? 22

$5 \quad$ Policy recommendations 24

5.1 Should the tax be kept, amended further, or repealed? 24

5.2 What does good tax policymaking look like?

5.2.1 Use a medium-term agenda for tax policy 25

5.2.2 Establish and publicise a robust tax policy process 25

5.2.3 Adopt rigorous policy appraisal standards 25

5.2.4 Create a two-way bridge between the political and technical
spheres

6 Conclusion 26

$\begin{array}{lr}\text { Appendix } & 27\end{array}$

$\begin{array}{lr}\text { References } & 29\end{array}$

Figures

Figure 1.1 Growth in the mobile money market in Uganda (2009 to 2019) 11

Figure 2.1 The Ugandan tax policymaking process 12

Figure 3.1 Tax-to-GDP ratios in sub-Saharan Africa (2008 to 2018) 15

Figure 3.2 Example of taxes and fees applied to a person-to-person (P2P) transfer 18 
Figure 3.3 Google Trends: search interest in Uganda (2018) 19

Figure 3.4 Trends in mobile money transaction volumes and values 21

Figure 3.5 Revenue performance of the mobile money tax, July 2018 to November 2020

Figure 4.1 Mobile money tax timeline

Figure A1 Abbreviated structure of the Ministry of Finance, Planning and Economic Development

Table

Table A1 Summary of 2018 Excise Duty Amendment Bill 


\section{Acknowledgements}

We are very grateful to Christopher Wales for nurturing this paper, for sharing substantial insights on tax policymaking processes, and for providing extensive comments on previous drafts. For useful comments and improvements on earlier versions, we thank Giulia Mascagni, Fabrizio Santoro and Laura Muñoz. We also thank three anonymous ICTD Working Paper Series reviewers for their insightful comments and contributions. We are also grateful to various senior officials from the Uganda Revenue Authority and the Ministry of Finance, Planning and Economic Development for their comments, their experiences, and their frankness in discussing some of the issues in this paper. Finally, we thank the Bill and Melinda Gates Foundation for providing funding to support this project.

\section{Acronyms}

BOU

DRM

DRMS

GOU MFPED

MNO

MP

P2P

TPD

URA
Bank of Uganda

Domestic revenue mobilisation

Domestic Revenue Mobilisation Strategy

Government of Uganda

Ministry of Finance, Planning and Economic Development

Mobile network operator

Member of Parliament

Person-to-person

Tax Policy Department

Uganda Revenue Authority 


\section{Introduction}

Mobile money is one of the most prominent and powerful financial sector innovations of the past decade for low-income countries, particularly in East Africa (Suri 2017). The service enables mobile phone users to deposit, transfer, and withdraw cash without having access to a traditional bank account. Initially dominated by inter-person transfers, the service has expanded to include a wide range of other payment capabilities, including utility bills, taxes, licences, and retail, and several governments have experimented with using mobile money to facilitate social transfers (Aron 2018). More recently, there have been a number of financial innovations using mobile money to deliver other products, such as microcredit and loans. A growing body of empirical studies have documented the potential benefits of the expansion of mobile money, including accelerating financial inclusion, increasing savings mobilisation and consumption, and improving resilience to shocks by reducing the transaction costs involved in domestic remittances (Jack and Suri 2016, 2014; Aron 2018; Munyegera and Matsumoto 2016; Riley 2018).

As the sector, and its turnover, has grown, governments are increasingly viewing mobile money as a convenient tax handle. ${ }^{1}$ This is especially true for governments facing pressures, both domestic and external, to increase domestic revenue mobilisation and reduce the reliance on aid and borrowing to fund public services. The resulting tax measures are often controversial and have drawn sharp criticism from those who fear that they will undermine the growth of nascent digital finance sectors and the development gains that (digital) financial inclusion is claimed to enable (Adegoke 2018; Ndung'u 2019; UNCDF 2018).

Uganda presents an interesting case study of this trend. On 1 July 2018, the government introduced an especially contentious new tax of 1 per cent on the value of all mobile money transactions. This formed one part of a package of excise duty amendments looking to mobilise more revenue from the telecommunications and financial sectors, including a new and unpopular charge of UGX 200 (US $\left.\$ 0.05^{2}\right)$ per day to access social media ${ }^{3}$ and increased tax rates on the fees charged by mobile money providers and financial institutions (Government of Uganda 2018a). ${ }^{4}$ The mobile money tax legislation was initially drafted such that every stage of a mobile money transfer was taxed - depositing, sending, receiving, and withdrawing the money. These were identified as separate, and thus individually taxable, transactions. In effect, one transfer between two users might have been taxed up to four times. After widespread public outcry and significant challenges in implementation, the tax rate was adjusted to 0.5 per cent and restricted to withdrawals in November 2018.

What was the origin of this ultimately flawed measure? What did the policymaking process look like? Were established policy processes bypassed or undermined? Who was involved and who was excluded?

These are the key questions we seek to answer in this paper. This paper examines and critiques the tax policymaking process followed during the introduction, and the later adaptation, of the mobile money tax. Through this case study, we highlight the risks posed by shortcomings in Uganda's current approach to tax policymaking. A well-engineered process

A 'tax handle' typically refers to a part of the economic system to which taxes can be attached.

1 US Dollar equates to approximately 3,700 Ugandan Shillings (UGX) (based on the average exchange rate in 2019). This exchange rate is used throughout the paper.

3 The Excise Duty Act in Uganda (see Government of Uganda 2018a) applies this tax to 'over the top services', which are defined in the Act as 'the transmission or receipt of voice or messages over the internet protocol network and includes access to virtual private networks'. In this context, the tax is applied to apps allowing instant messaging, video calling, and voice calling, which have replaced traditional phone calls and text messaging services.

4 See Table A1 in the Appendix for a full breakdown of the tax changes introduced through the Excise Duty Amendment Bill 2018 (Parliament of Uganda 2018a). 
does not guarantee good outcomes. However, we will argue that by establishing a few key fundamentals, governments can make the achievement of better policy outcomes more likely, and significantly decrease the risk of avoidable, often costly, errors in policy design. The relevance of this work extends beyond Uganda, as other low-income countries are considering introducing, or are experimenting with, taxes on mobile money services, and digital payments more generally. We expect this work to be of interest to policymakers facing similar challenges, particularly in the context of political regimes characterised by strong vertical accountability and patrimonial governance.

This paper contributes to two strands of literature: the study of tax policymaking; and analyses of the taxation of digital financial services. In the first strand, the process of designing, drafting, scrutinising, and implementing tax laws is relatively under-examined, particularly in the context of low- and middle-income countries. Wales and Wales (2012) give the most comprehensive and systematic comparative study of the entire lifecycle of tax policy development, across ten high-income countries. The authors find that, in general, the importance of a properly functioning tax policy process is under-appreciated and underresourced, with too little emphasis placed on engaging citizens on tax policy issues, weakening links between taxation and representation (Wales and Wales 2012).

Many of these issues are heightened in lower-income countries. Dedicated tax policy units, where they exist, tend to be constrained by the availability of reliable data and the capacity of staff to analyse this data, in addition to having relatively little specialised training on tax issues (Grote 2017). This can be complicated further by institutional rivalry between the authority responsible for revenue collection and those responsible for policy development (often housed in a ministry of finance). Revenue authorities hold the data and practical knowledge necessary for well-designed policy and commonly report to ministers of finance, but also derive significant bargaining power from their role in funding the state (Moore, Fjeldstad, Isaksen, Lundstøl, McCluskey and Prichard 2015; Arnold 2013). With respect to stakeholder engagement, the literature supports wide consultation to minimise damaging consequences and compliance burdens and to foster a sense of ownership and political buyin (Gordon and Thuronyi 2012; Wales and Wales 2012). However, tax reform in low-income countries tends to involve just a few trusted and well-informed experts (Arnold 2013). The empowerment of a wide range of voices in public tax debates is rare in the African context (Moore, Prichard and Fjeldstad 2018). Finally, research thus far has demonstrated the importance of strong institutions for successful tax reform, as these help to guard against opportunistic behaviour by developing reliable analysis in support of a well-articulated strategy (Cottarelli 2012). ${ }^{5}$

The second strand of literature is emergent, with only a few instances of papers examining the rationale for and impact of taxes on digital financial services, especially mobile money services, in lower-income countries. Clifford (2020) examines the motivations behind and 'unintended consequences' of mobile money taxation in Uganda, Côte d'Ivoire, the Republic of Congo, and Malawi through a largely qualitative approach based on semi-structured interviews. The author finds that the driving force has often been a desire to increase tax collection, as well as tackle perceived evasion in the informal sector by taxing a favoured payment method. Clifford (2020) argues that, as there are no tax-free thresholds and few alternatives for low-income earners (who typically do not have access to the formal banking system), these taxes are, by design, regressive. Anecdotal evidence also suggests that the livelihoods of mobile money agents have been affected as business slows. In addition, the author points to the depressed growth in mobile money transaction values post-tax, arguing that this will have negative implications for the corporate income and value-added tax bases, as the profitability of mobile money providers may be reduced (Clifford 2020). Ndung'u (2019) argues that the taxation of mobile-based transactions might threaten financial 
inclusion gains, increase incentives to use cash to avoid taxation, and may be (mis)interpreted as the government actively discouraging the use of these services. The author examines trends in the growth of electronic payments in Kenya, noting that growth in the share of electronic payments made using mobile phones appeared to slow after a new excise duty was introduced in 2013 . While the author acknowledges that this is rather weak empirical evidence, it is taken as a sign that higher tax rates discourage use, especially among cost-sensitive low-income earners, resulting in lower tax collection over time. Finally, Fuchs, Musuku and Symington (2017) study mobile money taxes in Pakistan and Tanzania through stakeholder interviews and focus-group discussions with customers and agents. The authors find that taxes were unlikely to have influenced demand for person-to-person (P2P) transfers, as the total tax burden was small (1-2 per cent of the amount transferred) compared to other transaction costs and there are few outside options. However, they also argue that taxes might discourage the broad adoption of more 'advanced' uses of mobile money, such as merchant payments and mobile credit. While these papers are suggestive of negative implications for the broader economy, financial inclusion, market deepening, and the welfare of low-income earners, they are not conclusive. There is a dearth of rigorous empirical work, for instance using administrative tax or mobile money user data, in-depth field surveys, or 'lab-in-the-field' experiments, ${ }^{6}$ to capture the true impact of these taxes.

In this paper, we contribute to the literature by examining, in detail, a specific example of the tax policymaking process in a low-income country. To our knowledge, this is one of the only papers to take such an approach. We also complement a recent review of the tax policymaking process in Uganda by Wales and Lees (2020), which examined the overall effectiveness of current practices and working arrangements (discussed in section 2). Our exposition of the current process establishes a benchmark against which to evaluate the case of the mobile money tax. In section 3, we explore in detail the motivations for the introduction of the tax, making links to the political dynamics at the time. We describe how this case diverged from the typical tax policy process in Uganda, indicating in section 4 what made this particular measure highly unusual. Finally, in section 5 we suggest possible remedial actions and give some policy recommendations to safeguard and strengthen the policymaking process.

Importantly, this paper does not attempt to conduct a thorough evaluation of the broader social and economic impact of the tax measure itself. This would require a robust empirical analysis of more granular data, to determine the impact on the users and usage of mobile money, financial inclusion, and economic well-being. To our knowledge, such a study has not yet been done, although we are planning to undertake such research in the coming months. ${ }^{7}$ Instead, the objective of this paper is to identify where the tax policy process diverged from established norms, and to draw some lessons on what can be done to reinforce this process in future. 


\section{Study context and methodology}

\subsection{The importance of mobile money in Uganda}

Mobile money services were first introduced in Uganda by MTN in 2009 and, since then, the sector has seen significant growth. During the first year of operation, the number of registered accounts grew to 770,000 and the total value of transactions amounted to approximately UGX 133 billion (US\$36 million) over the year. After MTN, other mobile network operators (MNOs) soon introduced similar services and seven licences for mobile money services have subsequently been issued, although the industry is still dominated by MTN and Airtel. ${ }^{8}$

Within a decade, the number of registered, active accounts had surpassed 16 million $^{9}$ and the total annual value of transactions had grown to UGX 73 trillion (US\$20 billion) (Bank of Uganda 2021). To put this into context, in 2019, Uganda's working-age population was 22.8 million ${ }^{10}$ and 57 people in every 100 had a mobile cellular subscription (World Bank 2020a). Figure 1.1 highlights the dramatic growth in the uptake and usage of mobile money accounts, which shows little sign of slowing. This growth is due, in part, to the accessibility of mobile money, enabled through a national network of roughly 212,500 registered mobile money agents ${ }^{11}$ who are markedly more prevalent than more traditional financial service providers, such as commercial banks. Surveys have indicated that whereas 54 per cent of the population had a mobile money point-of-service within one kilometre of their home, just 16 per cent of the population had a point-of-service for a traditional bank (Bank of Uganda 2017).

The rise of mobile money in Uganda correlates with expanded financial inclusion (DemirgüçKunt, Klapper, Singer, Ansar and Hess 2018). The 2018 FinScope survey ${ }^{12}$ showed that the share of the adult population with access to an account from a formal provider, including mobile money operators and commercial banks, has almost doubled since 2009. Mobile money is by far the most popular formal service, with 56 per cent of adults using this, versus just 11 per cent using commercial bank services, the next most common (FSDU 2018). Recent empirical research indicates that mobile money plays an important role in the financial well-being of users. Usage has been linked to improved resilience of households in the face of shocks to income (Jack and Suri 2014) and increased household per capita consumption (Jack and Suri 2016; Munyegera and Matsumoto 2016). Increased remittances, and improved risk-sharing through a larger, more accessible network of family and friends, appear to improve consumption smoothing among mobile money users, relative to non-users (Jack and Suri 2014; Jack, Ray and Suri 2013; Munyegera and Matsumoto 2016; Riley 2018). While the reliability of some of these socioeconomic impacts has been questioned (see, for instance, Bateman, Duvendack and Loubere (2019)), the financial inclusion of the poor seems more likely to have positive than negative effects, if not truly transformative impacts (Duvendack and Mader 2020).

\footnotetext{
8 NITA-U (National Information Technology Authority - Uganda) data (2018) indicates that among mobile phone owners, 74 per cent use MTN as their service provider, and 62 per cent use Airtel (multiple selections are possible).

$9 \quad$ For an account to be considered as 'active', it must have been used to perform at least one person-to-person payment, bill payment, cash in, cash out, or airtime top up during at least 90 days prior to the end of December 2019. At the end of 2019, Uganda's mobile money sector reported over 27 million total registered accounts.

This represents 52 per cent of the total population.

As of December 2019 (Bank of Uganda 2021).

This is a nationally representative survey conducted by the Finmark Trust in partnership with Financial Sector Deepening Uganda (FSDU). Similar surveys were conducted in 2007, 2009, and 2015.
} 
Figure 1.1 Growth in the mobile money market in Uganda (2009 to 2019)

(a) Registered mobile money accounts

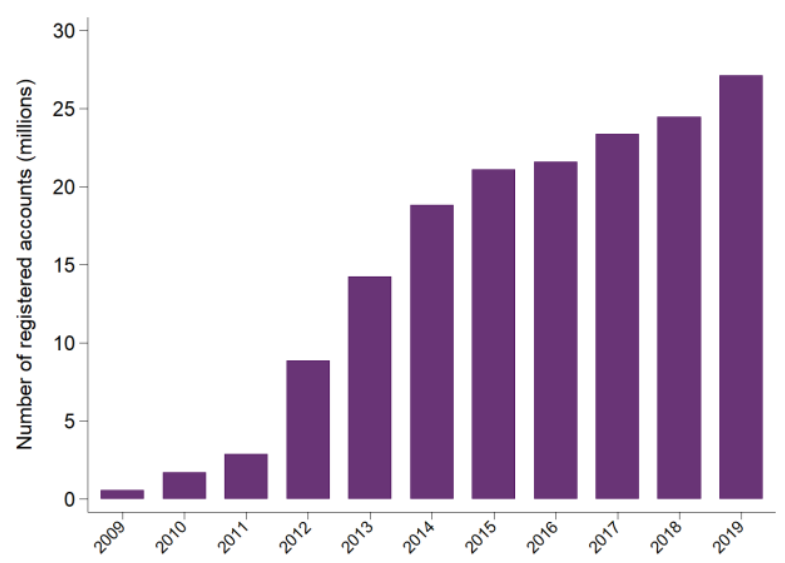

(b) Transaction volumes and values

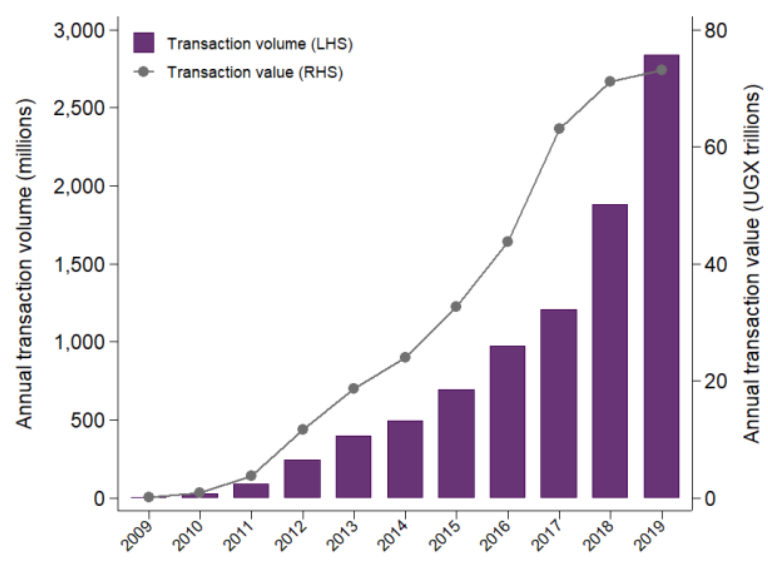

Source: authors' calculations using data from the Bank of Uganda (2021).

\subsection{Methodology}

This study is primarily qualitative in approach and many of our findings are based on interviews with senior government officials (principally at the Ministry of Finance, Planning and Economic Development and the Uganda Revenue Authority) and other close observers with substantial experience of Ugandan tax policymaking. We also rely heavily on our own recollections of the policy process. These insights are complemented by textual analysis of publicly available government documents (including relevant legislation, parliamentary records, and government policies), academic articles, and newspaper reports. For our description of the current approach to tax policymaking in Uganda (see section 2), we draw on previous work from Wales and Lees (2020). Finally, we present some descriptive statistics data published by the Bank of Uganda (BOU) and data on tax revenue collection provided by the Ministry of Finance, Planning and Economic Development (MFPED) and the Uganda Revenue Authority (URA).

\section{The Ugandan tax policymaking process}

Uganda currently has the foundations of a strong, well-structured system for policy development, providing for an orderly progression from an idea for change to the implementation of a final tax measure (Wales and Lees 2020). Tax policy development in Uganda follows a series of distinct phases, closely linked to the annual budget cycle, as illustrated in Figure 2.1. This process has emerged through a combination of historical influences (it has similarities to Westminster practices), cultural norms, and Ugandan political requirements. In principle, the process gives longer-term strategic plans a role in guiding the development of the revenue strategy and allows for the early integration of external inputs. It incorporates elements of 'best practice' in tax policymaking, such as stakeholder consultation, analysis of revenue estimations for proposed measures, close working relationships with the legislature, and feedback loops (Wales and Wales 2012; Gordon and Thuronyi 2012; Arnold 2013). It also closely resembles New Zealand's Generic Tax Policy Process (GTPP), which places significant emphasis on the early development of policy ideas, extensive consultation, intra-government collaboration, and post-implementation review (Tax Working Group 2018). The GTPP has been singled out as a particularly strong example of a tax policymaking process (Wales and Wales 2012). 
Figure 2.1 The Ugandan tax policymaking process

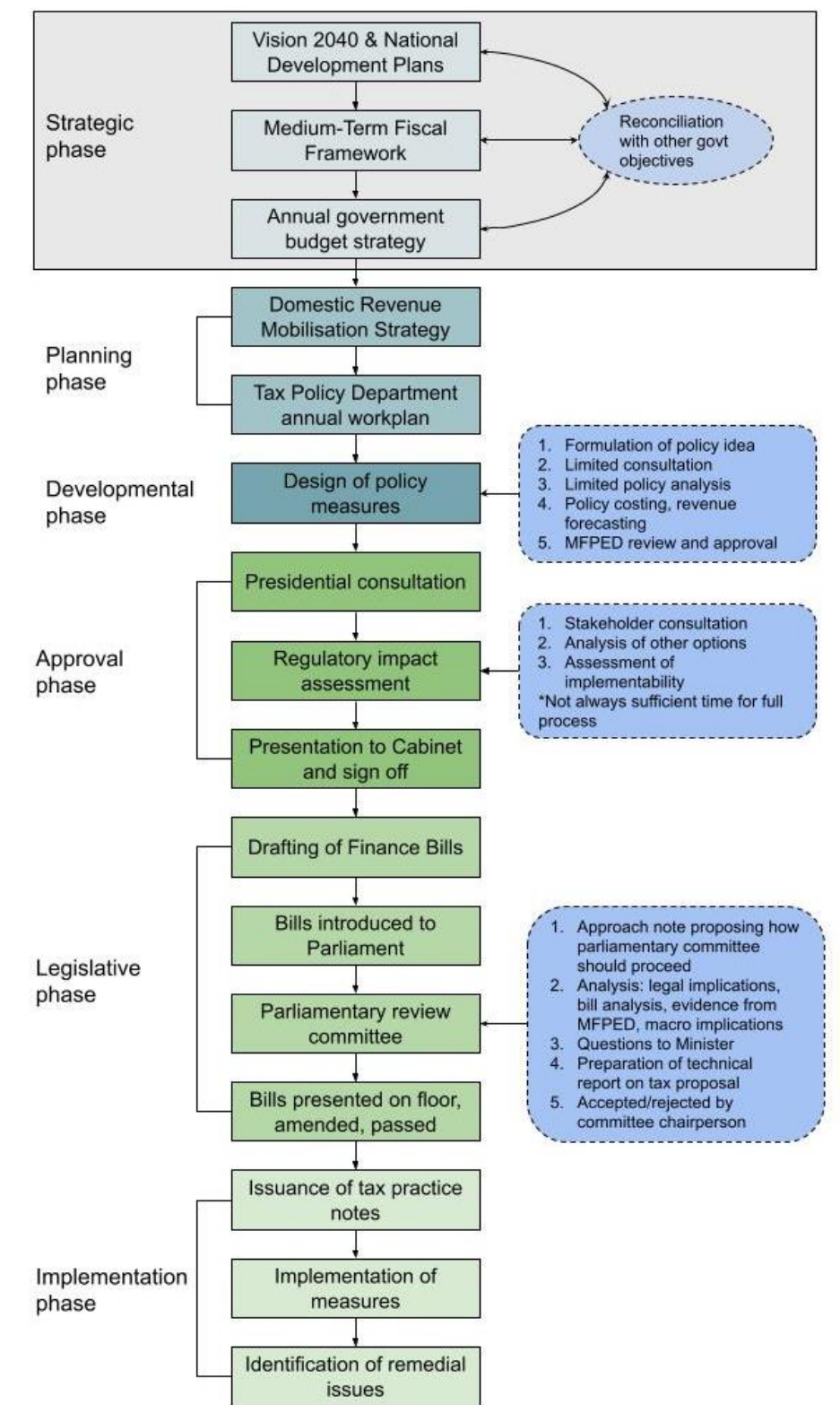

Source: authors' re-creation, from Wales and Lees (2020).

In practice, however, certain phases are under-developed, truncated, or bypassed in the interests of political expediency. Below, we briefly describe the process followed by a typical tax measure, noting where current practices generally fall short of aspirations. This then serves as a baseline against which to assess the process in relation to the mobile money tax in section 3 . We start with the planning phase, where the tax policy work really begins. Tax policymakers are typically less involved in the strategic phase (the grey shaded area in Figure 2.1), which is determined by other parts of the Government of Uganda (GOU). Mentions of taxation in these strategic plans are often limited to a target tax-to-GDP ratio, and they are usually silent on options for using tax policy as a lever in achieving broader objectives. 


\subsection{The planning phase}

Tax policy development is tightly controlled by the MFPED, which houses the Tax Policy Department (TPD) under the Directorate of Economic Affairs (Appendix Figure A1 shows an abbreviated organisational structure of MFPED). The MFPED has been recognised as a 'pocket of effectiveness' within the GOU, as it is usually able to deliver on its mandate in a context where this is not the norm (Bukenya and Hickey 2019). The tax policy agenda in Uganda should, in theory, be reconciled with other key government strategies, such as the Vision 2040 and associated National Development Plans. In reality, the direct influence of other GOU strategies and policies on the revenue strategy is relatively slight (Wales and Lees 2020). Ensuring that tax policy is compatible with other government objectives is only done sporadically, and engagements between TPD and other parts of the GOU are usually limited and unstructured.

TPD's annual workplan is largely determined by the budget cycle, in terms of both timing and content. While this improves the predictability of work, TPD's involvement in crafting the budget strategy is limited to providing a projection of tax revenues as an input for determining the resource envelope (Wales and Lees 2020). Partly as a result, the policy work is generally biased towards developing short-term, revenue-raising measures. Somewhat unusually, the development of the Domestic Revenue Mobilisation Strategy (DRMS), Uganda's mediumterm revenue strategy, included several inputs from other ministries and other parts of the MFPED, facilitated through the establishment of the Domestic Revenue Mobilisation Working Group which brought together several other government bodies and private sector associations. This strategy recognises the importance of establishing a medium-term vision for tax policy and presents a valuable opportunity to redress the balance between short-term demands and medium-term objectives. Adopting a longer-term vision for the tax system, closely linked to other government objectives, recognises the role that the tax system plays in promoting economic growth, employment creation, and development. This also helps to guard against frequent, incremental, and crisis-driven reforms, which can undermine the sustainability of the tax system (Gordon and Thuronyi 2012).

\subsection{The developmental phase}

Tax policy proposals in Uganda generally emerge from three sources: (i) research done by TPD; (ii) an annual submission from the URA; and (iii) external stakeholders, often in the form of ad hoc submissions or appeals. In principle, TPD should analyse the wider economic, social, distributional, and welfare effects of all proposals. In practice, this work is often limited to estimating the revenue impact, due to both time and resource constraints. During this phase, TPD collaborates closely with the URA, factoring their 'on-the-ground' experience of tax administration, potential loopholes, and developments at the East African Community level into policy analysis. Opportunities for other detailed, targeted stakeholder consultations are limited, and the potential value of such consultations is generally under-appreciated (Wales and Lees 2020). TPD is also frequently asked by senior MFPED officials to analyse the feasibility of new revenue proposals in a short timeframe, resulting in responses for which the underlying research is often not sufficiently robust. Once proposals have been appraised, they are then considered by the senior management of the MFPED. The submissions usually include a brief description of the measure, its objective, and the estimated revenue impact.

\subsection{The approval phase}

Subsequently, the measures approved by the leadership of the MFPED are passed to Cabinet. In principle, this gives the Cabinet Secretariat an opportunity to check the quality of proposals and carry out a rigorous regulatory impact assessment, including further stakeholder consultations and an assessment of other policy options (Wales and Lees 2020). 
This is intended to sift out proposals for which the evidence is insufficient or improperly analysed. In practice, tax proposals are frequently tabled at Cabinet late in the budget cycle, compromising the ability of the Secretariat to add significant value. The requirement for a full regulatory impact assessment to be completed is often bypassed (Wales and Lees 2020). Proposed tax changes usually become public knowledge at this stage.

\subsection{The legislative phase}

Once approved by Cabinet, legislation is drafted, typically under significant time pressure, before the bills are introduced to Parliament for the first reading. A parliamentary committee is then appointed to consider the evidence in favour of a proposal, hold hearings to gather more information, and feed its recommendations back to members of Parliament (MPs). In the plenary sessions, tax issues are usually debated in terms of their revenue-raising potential and likely impact on constituents, with less discussion of technical elements (Wales and Lees 2020). As stipulated in the Public Financial Management Act, Parliament must approve the budget and related bills by 31 May, and these are then passed to the President for his assent.

\subsection{The implementation phase}

Measures typically come into force at the start of the new financial year on 1 July. At this stage, the URA often issues guidelines or practice notes explaining how to interpret and comply with the new laws. In practice, the short timeline between parliamentary approval and implementation can create challenges, particularly where the URA has not had sufficient time to develop and introduce new systems or protocols for its staff. Post-implementation review is not a formal, scheduled part of the process. Usually, measures are evaluated based on their performance against revenue targets, without a detailed assessment of the wider consequences of reforms (Wales and Lees 2020).

\section{The approach to the mobile money tax}

\subsection{Planning phase: the budgetary background}

Despite year-on-year nominal increases in revenue collection achieved by the URA and TPD, the consensus in early 2018 was that Uganda's tax effort remained some way below its revenue potential. ${ }^{13}$ Research conducted during the development of the DRMS ${ }^{14}$ highlighted that, without intervention, tax revenues were unlikely to be able to support Uganda's growth and development ambitions (Government of Uganda 2020). Tax revenue collection, just short of 11 per cent of GDP in 2017, lagged behind regional peers (see Figure 3.1). The discrepancy between expenditure and revenue was substantial and growing, leaving Uganda with a considerable budget deficit of 4.75 per cent of GDP in the financial year 2017/18. This increased pressure on the Ugandan Government to borrow funds externally and domestically. From 2014 to 2019, Uganda's debt-to-GDP ratio rose by over ten percentage points, while the tax-to-GDP ratio increased by approximately two percentage points (Government of Uganda 2020).

For instance, see World Bank (2018), Langford and Ohlenburg (2016), and Government of Uganda (2020). The final strategy paper was launched in late 2019 and published in February 2020. However, the process of developing this document began in 2017. 


\section{Figure 3.1 Tax-to-GDP ratios in sub-Saharan Africa (2008 to 2018)}

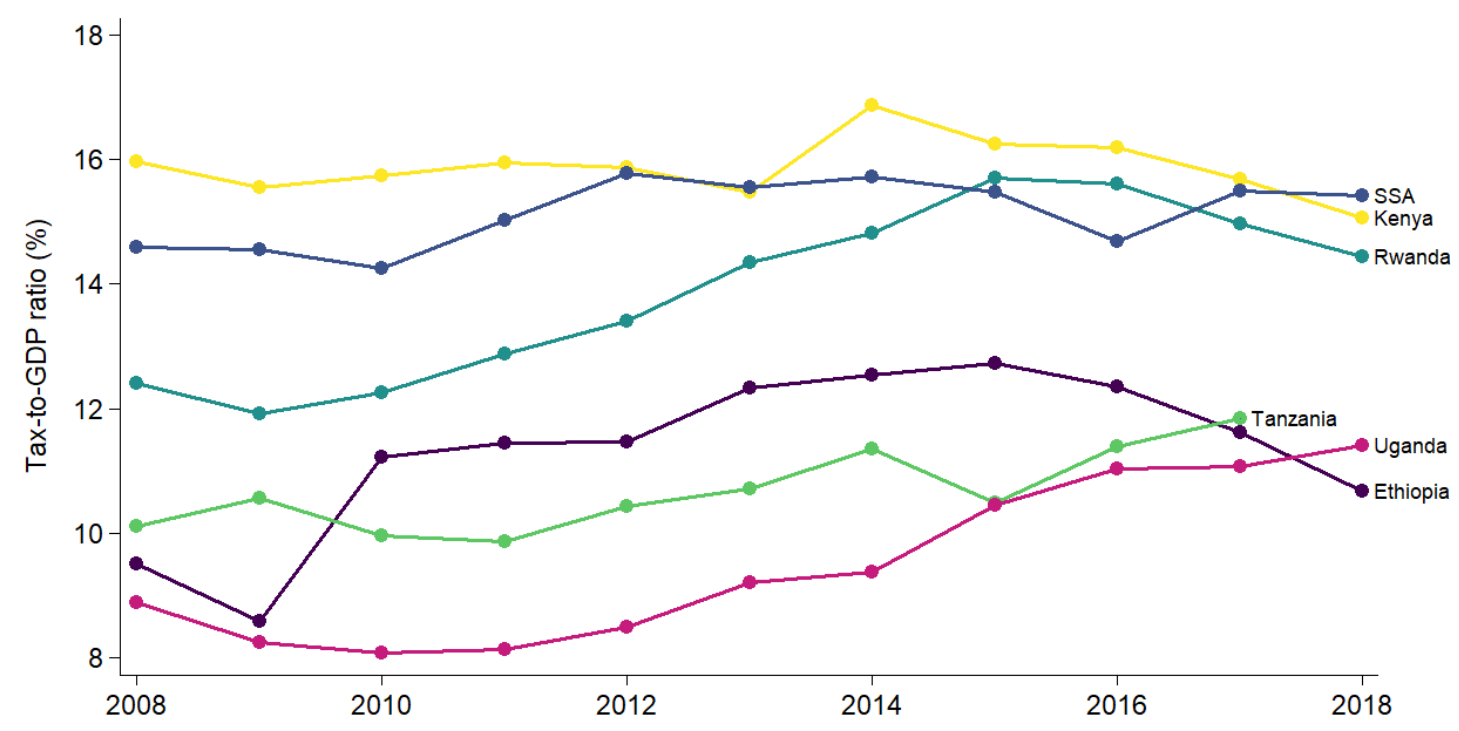

Note: Each line reflects the tax-to-GDP ratio, which excludes non-tax revenues. 'SSA' reflects the average tax-to-GDP ratio across sub-Saharan African countries. Source: authors' calculations with data from the ICTD/UNU-WIDER Government Revenue Database (2021).

Against this background, improving domestic revenue mobilisation (DRM) and reducing the reliance on debt financing had been identified as priorities by both the GOU and its development partners. There was a prominent, high-level political commitment to mobilising more tax revenue. The IMF highlighted improved DRM as a key component of its structural support programme in Uganda and was frequently encouraging policymakers to 'expand and diversify the revenue base', in Uganda and beyond (Adegoke 2018). As Moore (2020: 25) argues, this is intended as a 'diplomatic way' of encouraging governments to reign in tax exemptions but is often misinterpreted to mean 'get more people to pay tax'. Similarly, the World Bank dedicated its Economic Update, released in May 2018, to options for raising more revenue, particularly noting challenges in tackling informality and capacity constraints in tax administration. Uganda has a large informal sector, accounting for over half of all economic activity (Uganda Bureau of Statistics 2020), which is often identified as a major structural constraint to revenue growth. ${ }^{15}$

Tax policymakers faced pressures from many sides in early 2018. Unanticipated expenditure requirements, and the rejection of several revenue-raising tax proposals, created pressure to find new sources of revenue late in the budget cycle. In part, the search for new revenue sources is a symptom of weaknesses in the budget process. The expenditure side of the budget is usually given precedence, without adequately considering the likely tax performance in tandem. Without a sufficiently strong and assertive policymaking process, these pressures can lead to tax policy changes being pushed through without proper examination, to 'fill a gap'. This certainly seems to have been the case for the mobile money tax, which did not feature in TPD's initial workplan.

\subsection{Developmental phase}

\subsubsection{Policy initiation and motivation}

Normally in the Ugandan policymaking process tax measures are driven by the MFPED with the close involvement of the URA (see section 2). Unusually, this measure emerged on the

15 Moore (2020) gives a detailed and thorough analysis of the problems with this narrative about the informal sector being 'untaxed'. 
initiative of the President's Office. On 12 March 2018, the Minister of Finance was sent a letter signed by the President, Yoweri Museveni, criticising tax officials for a 'lack of seriousness' in identifying new sources of tax revenue (The Independent 2018). Among other issues, the President documented two concerns relating to the telecommunications sector: (i) the lack of excise duties applied to communications over internet platforms and (ii) 'false declarations' of earnings from telecommunication service providers to reduce their tax liabilities (Daily Monitor 2018a). Later, President Museveni wrote on his personal blog that the mobile money business is a 'convenient source' of revenue, and that 'telephone companies [...] have been concealing possible tax sources from the govt [sic] and have been aiding tax evasion. They have been hiding the movement of money in and out of the country' (Museveni 2018b). Importantly, the President's Office does not have a separate policy unit, nor does the President have a dedicated advisor on tax policy or revenue matters. ${ }^{16}$ The proposal arose directly from the President's Office, towards the end of the normal budget cycle. This was unprecedented: a senior government official said they had 'never seen a measure introduced in this way'.

Cognisant of budget financing concerns, some prominent politicians appeared to endorse the narrative that the telecommunications sector was under-taxed. For instance, during the parliamentary debate on this measure, the Deputy Speaker asked MPs to consider whether it was 'okay that this sector is not taxed at all [...] that you have transactions going into trillions of shillings that are not attracting tax?' (Parliament of Uganda 2018c: 31). The URA had reported that revenues from excise duties on airtime and calls were below targets, and on a downward trend as citizens increasingly used apps and internet platforms for calls and messaging (Uganda Revenue Authority 2018). It was believed that a tax on mobile money (in addition to a tax on social media apps) would increase the overall tax contribution from the sector, as well as safeguard revenues as technologies evolved. The Chairperson of the Budget Committee highlighted this in Parliament, saying that 'business is shifting from analogue to digital platforms [...] the taxman should equally shift' (Parliament of Uganda 2018c: 21). The Parliamentary Finance Committee employed a similar argument, reporting that mobile money is an 'efficiency gain and should be taxed' and that the measure would 'generate more revenue and broaden the tax base' (Parliament of Uganda 2018b: 13, 14).

It was also argued by the President and politicians that mobile money was a convenient mechanism to draw informal sector players into the tax system. The President wrote on his blog that the informal sector is 'never taxed' and a tax on mobile money would ensure a 'modest contribution' (Museveni 2018a). During parliamentary debates, the State Finance Minister for Planning ${ }^{17}$ said that 'most of these people who are involved in mobile money transactions are not taxed anywhere else. That is where they interact with the economy, they are in the informal sector and you can never find them' (Parliament of Uganda 2018c: 29). It was believed that a tax of 1 per cent was small enough to support the budget, without hurting the users.

In hindsight, these motivations appear incongruous, as the proposed tax measure would not simultaneously tackle all the issues. For instance, while many governments face challenges in ensuring that the telecommunications sector pays its fair share (Matheson and Petit 2017), the proposed tax was ultimately levied on the consumer. Thus, it was a very indirect and over-simplified way to target the providers of mobile money. Inconsistent and contradictory rationales for the tax measure illustrate that this multi-faceted issue was not understood or approached systematically.

16 The President Office's does have a Presidential Advisory Committee to the Budget (PACOB), but this unit does not engage in revenue matters or policymaking. They are more of a lobby group on budget allocations.

17 The State Finance Minister for Planning is one of four state ministers at the MFPED. They form part of the Top Management and report to the Minister of Finance (see Appendix Figure A1 for an organisational chart showing the structure of MFPED Top Management). 


\subsubsection{The response from the MFPED}

As early as 2016, the President had warned that Uganda would start to take stronger action against perceived tax evasion by telecommunications firms (The Independent 2016). Technical officials may not have anticipated the extent of the political determination to tackle this issue, nor the demand for measures to reduce opportunities for potential tax evasion in the informal sector. As the policy direction had been decided at the highest political level, policymakers were obliged to follow rather than to lead.

Nevertheless, officials from the MFPED did attempt to produce objective, technical analysis to show that the measure, as originally conceived, was unsuitable, and to offer alternatives. This analysis appears to have failed to ultimately influence the policy direction. There was a strong bias, even in the MFPED, towards securing a new source of revenue, rather than determining whether any potential economic and social harms would outweigh the revenuegenerating benefits. While TPD, and the MFPED more generally, has strong technical and modelling capacity, there is, in general, a lack of demand from senior officials and politicians for this level of analysis to be done. This is recognised in the DRMS, which highlights that tax policy has historically been driven by short-term revenue pressures, with limited appetite for considering the full economic, distributional and welfare impacts of policy changes (Government of Uganda 2020).

Although time was short for the policy development process, various consultations were held with the URA, the BOU, and the telecommunications sector to discuss the proposed mobile money tax. TPD and the URA worked closely together on revenue estimations, and the technical officials were aligned on many issues, including the need to consult the public through various civil society organisations and private sector associations. The sector was, unsurprisingly, opposed to the measure and attempted to demonstrate its weaknesses. However, counterarguments from the MNOs were not seen as especially persuasive or compelling. Through the experience of previous changes in fee-based excise duties, officials felt that MNOs adjust their tariff structures to compensate for taxes and to safeguard their profitability.

Weaknesses in the tax policy process, and insufficient policy analysis, resulted in a flawed tax measure being passed to Cabinet and Parliament. As the legislation was initially drafted, the tax was imposed four times on a single mobile money payment - depositing, sending, receiving, and withdrawing the money were all treated as separately taxable transactions. Figure 3.2 illustrates this (mis-)application. The second column shows the assumed tax base for an illustrative transfer of UGX 20,000 (US\$ 5.40) between two mobile money users. A 1 per cent transaction tax applied to each of these stages results in an overall tax burden of UGX 800 (US\$ 0.22). The final column gives an example of the true, additional economic value created through a transfer, from the fees levied on the transaction. These fees amount to UGX 1,450 (US\$ 0.39) in total. A 1 per cent transaction tax thus increased the overall cost of this illustrative transaction by 55 per cent. In an effort to be comprehensive, the tax was initially applied multiple times to one transaction, seemingly misunderstanding how the mobile money industry operates and where profits are made. This misconception arose in parliamentary debates as well, where the State Finance Minister for Planning drew a comparison between the total annual value of mobile money transactions and Uganda's gross domestic product (Parliament of Uganda 2018c). This comparison seemed to imply that the total transaction value equated to a significant source of untapped revenue. However, this is really a reflection of the movement of money, rather than the 'creation' of new value in the economy. 


\section{Figure 3.2 Example of taxes and fees applied to a person-to-person (P2P) transfer}
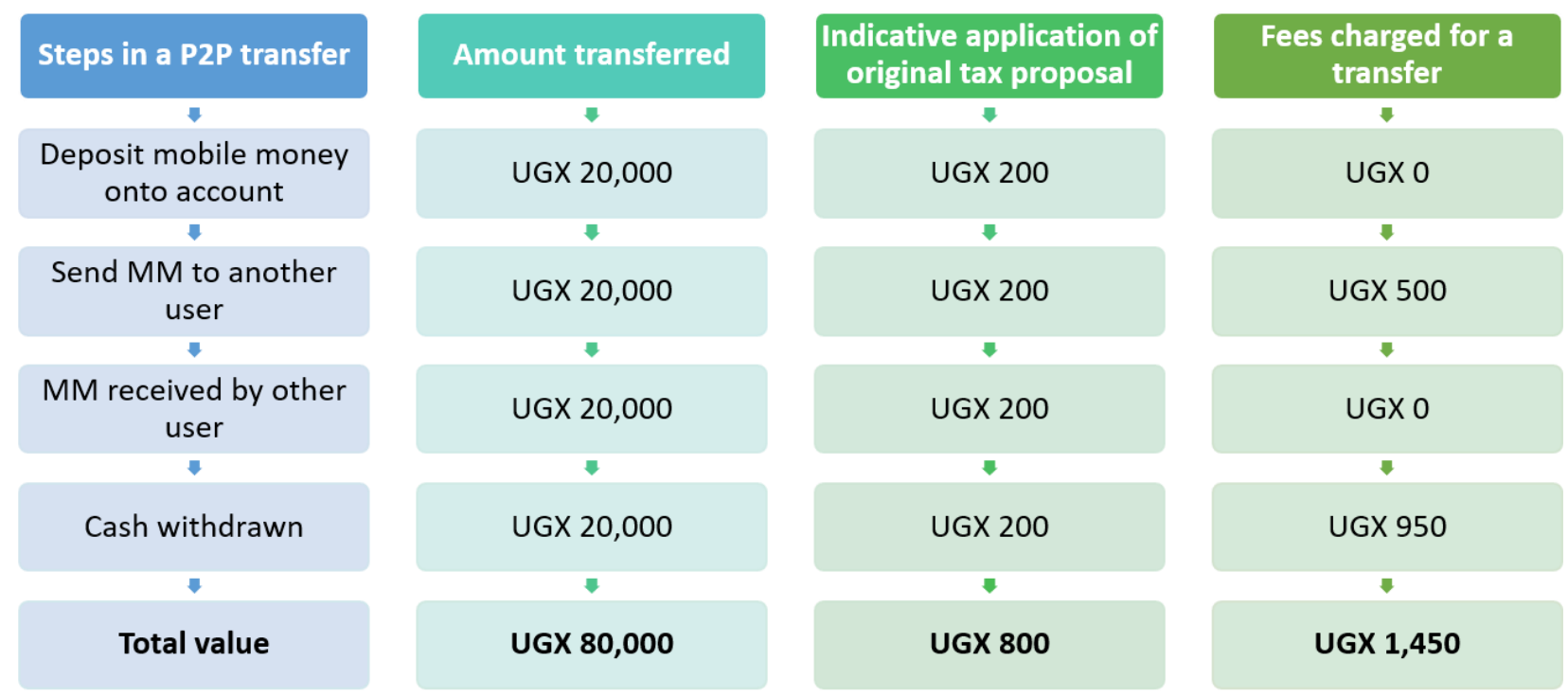

Tariff sources: MTN Mobile Money tariffs taken in April 2021 (www.mtn.co.ug/insight/mobile-money-tariffs/)

Uganda's Public Financial Management Act stipulates that the Minister of Finance must present tax bills to Parliament for a first reading in the first week of April, and the final budget must be approved before 31 May. A political direction emerging on 12 March thus does not leave much time for detailed and rigorous analysis. The source of this proposal, as well as the sense of urgency given the overall budgetary position, added to its weight. Despite the unease of a number of senior officials, the mobile money tax was ultimately included in the tax bills (along with the social media tax). The normal policymaking process did not seem robust enough to withstand the pressure of the moment.

\subsection{Legislative phase: Parliamentary process and debate}

Despite the strong reservations of some senior officials from the MFPED, the URA, and the $\mathrm{BOU}$, as well as appeals to study the issue further before passing legislation, the measure was approved by Cabinet and passed to Parliament. The resulting Excise Duty Amendment Bill was first read in Parliament on 3 April, then referred to the relevant parliamentary committee for review. After holding hearings with a variety of stakeholders, including the URA, civil society organisations, and MNOs, the committee recommended that the Bill be passed at the second reading on 30 May, without proposing any amendments to the mobile money tax provisions (Parliament of Uganda 2018b). MPs questioned the impact on the poor and financial inclusion, as well as the practicality of enforcing the measure, asking whether users would be taxed multiple times for one transaction (Parliament of Uganda 2018c: 14, $29,30)$. These concerns were not given satisfactory answers by either the committee chairperson or representatives from the MFPED. The Bill was passed without amendments. Almost immediately, the Minister of Finance appeared to distance himself from the measure and was quoted in the press saying that the tax 'passed in error', that the rate should have been 0.5 per cent, and that the tax should rather be charged on mobile money providers as that is where the revenues lie (Wamala 2018). This is strongly indicative of a split in government, chiefly between the technical and the political spheres.

The significant gap between the first and second reading should have provided ample opportunity for opposition to mobilise against the proposal. On 3 May 2018, the Civil Society Budget Advocacy Group (CSBAG) began a nationwide campaign against the proposed tax. They argued that it would disproportionately affect poorer citizens and that the tax would frustrate progress on paying taxes, utilities, and state transfers via digital means (CSBAG 
2018). These efforts did not rally widespread citizen engagement and the tax proposal seemed largely absent from the general public discourse at the time.

As an indication of this, Figure 3.3 shows Google search interest from Uganda in the terms 'tax', 'mobile money' and 'social media' throughout 2018. ${ }^{18}$ We include the term 'social media' as a comparison point, since this tax proposal also drew significant criticism and public ire. Google Trends gives the relative popularity of a search query for a defined location and time period. The data is indexed to 100, where 100 indicates the maximum search interest across the terms, time period, and geographical area. ${ }^{19}$ We assume that search indicators provide representative information about the behaviours of the literate and internet-enabled segment of the population (who may be more likely to be mobile money users $^{20}$ ). There is relatively limited interest in these terms before July, even in May when the proposals were discussed in Parliament. Search interest for 'tax', 'mobile money' and 'social media' all peak in the week starting 1 July 2018, with another spike in search interest for 'mobile money' in October, correlating to the time of the later amendment.

\section{Figure 3.3 Google Trends: search interest in Uganda (2018)}

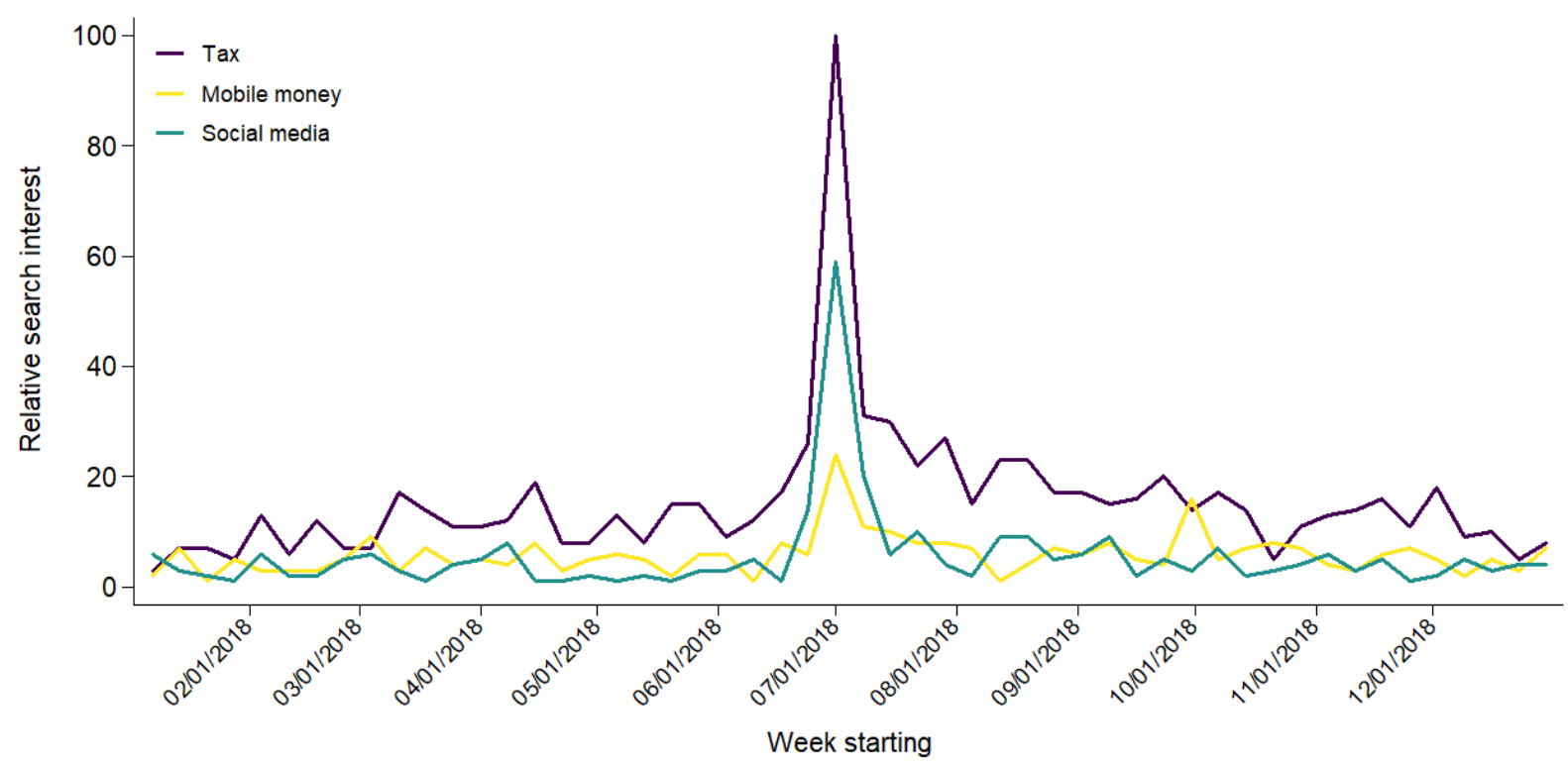

Source: authors' calculations using data from Google Trends (2021).

Mobile money providers were notably absent from the public debate at the time, although they did lobby Parliament in private. Before the tax was implemented, the only public statement from the providers simply indicated which transactions would be taxed from 1 July 2018 (Reuters 2018b). It is possible that providers, aware that the tax would ultimately fall on consumers, had assessed that any subsequent fall in transaction volumes would not substantially affect the overall profitability of their mobile money business. Indeed, this measure may have been viewed as less damaging than potential alternatives. Mobile money providers are also dependent on the government for the renewal of their business licences, and so naturally want to maintain a cooperative and cordial relationship.

\footnotetext{
18 Google Trends data on search terms only captures that exact term, and so the resulting graphs only reflect Englishlanguage searches for these terms.

19 A score of 100 indicates the week with the most searches for a particular topic, and zero indicates that a given week did not have sufficient search volume for the term.

20 For instance, Riley (2018) shows that adopters of mobile money in Tanzania are typically educated, wealthier, urbanised, and younger.
} 


\subsection{Implementation phase}

\subsubsection{Public response}

There was an immediate public outcry following the introduction of the tax on 1 July, with various stakeholders voicing concerns about double taxation, financial inclusion, job losses among mobile money agents, and the burden on the poor (Adegoke 2018; Reuters 2018a). Civil society organisations, together with journalists, students, and activists, mobilised significant protests and demonstrations against the new taxes. The social media tax, which was viewed as a form of digital repression and censorship (Boxell and Steinert-Threlkeld 2019), was the main source of outrage. This had a strong influence on the public perception of the mobile money tax, which was protested under many of the same banners. These events dominated the headlines domestically and attracted the attention of international media. A public opinion survey of nearly 3,000 people conducted in the second week of July found that 98 per cent of respondents did not support or were strongly opposed to the mobile money tax (Whitehead 2018). ${ }^{21}$

This period also demonstrates the value that consultation and industry knowledge, as well as the practical experience of tax administrators, can bring to policy development.

Implementation of the mobile money tax was initially difficult and erratic. At first, the tax was applied indiscriminately to all mobile money transactions. On 4 July, the URA communicated that this was a mistake: the tax should not have been applied to deposits, to transfers from personal bank accounts to mobile money accounts, or to the payment of other taxes with mobile money. ${ }^{22}$ This again suggests weaknesses in the policy design process as such misunderstanding should have been ironed out in the process of drafting legislation.

The President announced on 4 July that the rate of 1 per cent was gazetted in error and that the rate should have been $0.5 \mathrm{cent}$, and that the tax only applied to withdrawals (Museveni 2018a). He directed the URA to refund those who had initially paid the tax at the rate of 1 per cent. However, the URA was not legally mandated to pay refunds, as, until the new law was gazetted in November, transactions were taxed at the legislated rate. This caused further confusion and anxiety among citizens as they began to expect refunds which could not be provided.

\subsubsection{The amendment process}

Following the strong public disapproval and pressure, on 12 July the President requested that Parliament 'correct' the tax measure (Museveni 2018b). The Speaker of Parliament urged government officials to expedite an amendment to the Excise Duty Act, to 'harmonise the existing law [...] with current demands' (Parliament of Uganda 2018d). Four days later, Cabinet communicated a decision to limit the mobile money tax to withdrawals and to halve the rate. The State Finance Minister for Planning reportedly asserted that, despite lowering the rate and limiting the number of taxable transactions, the tax would raise UGX 118 billion (US\$ 32 million), UGX 3 billion more than initially projected (Daily Monitor 2018b). This inconsistency cast doubt on the credibility of the methodology used to generate the original revenue estimations.

The Finance Minister introduced an amendment in Parliament on 19 July, which was then referred to the Finance Committee, who, following parliamentary procedure, had 45 days to report back. The committee subsequently consulted with 15 organisations, including telecommunications firms and the BOU, who urged Parliament to drop the tax (The Observer

\footnotetext{
$21 \quad$ The survey was not nationally representative, with a bias towards young, relatively educated people living in the Central region of Uganda (characteristics that generally correlate with mobile money use).

22 https://twitter.com/mtnug/status/1014917634683531264?s=20
} 
2018). The committee, however, concluded that the measure was necessary to raise revenues to support the budget and recommended that the Amendment Bill be passed. The Bill was tabled again in the last week of September, but the vote was delayed as a quorum of 126 MPs were not present (New Vision 2018). MPs voted on the final Bill on 2 October, and it passed with 164 in favour and 124 against. Out of 458 MPs, just 288 were present on the day of the vote. The President assented to the new Bill on 25 October and the change was implemented from 17 November, once the new law was gazetted. ${ }^{23}$

\subsection{Revenue performance}

Figure 3.4 shows the monthly total value and volume of mobile money transactions before and after the introduction of the tax. Transaction values initially decline sharply, although they show some recovery to pre-tax levels over time. In contrast, transaction volumes rise around the introduction of the tax, although this is likely to be driven, at least initially, by the need to pay the social media tax with mobile money. Despite this early fall in the total value of transactions, and various implementation challenges, the tax was successful with respect to its original aim of raising revenue to support the budget. Within six months of implementation, the original revenue target for FY 2018/19 of UGX 115 billion (US $\$ 31.5$ million) had been reached. In addition, since the burden of collecting the tax was passed on to the mobile money providers, this tax is relatively efficient from the perspective of the URA and the MFPED, as the cost of collection is fairly minimal. Total revenue collections from the mobile money tax in FY 2018/19 were 137 per cent of the original revenue target (Uganda Revenue Authority 2019). The divergence between actual collections and the original forecast casts some doubt on the validity of the underlying assumptions and suggests that certain issues, such as price sensitivity and product substitutability, were not adequately considered in the forecasts. These weaknesses were in part due to misconceptions, especially among politicians, about how the industry operates, rather than poor modelling capacities within the MFPED.

\section{Figure 3.4 Trends in mobile money transaction volumes and values}

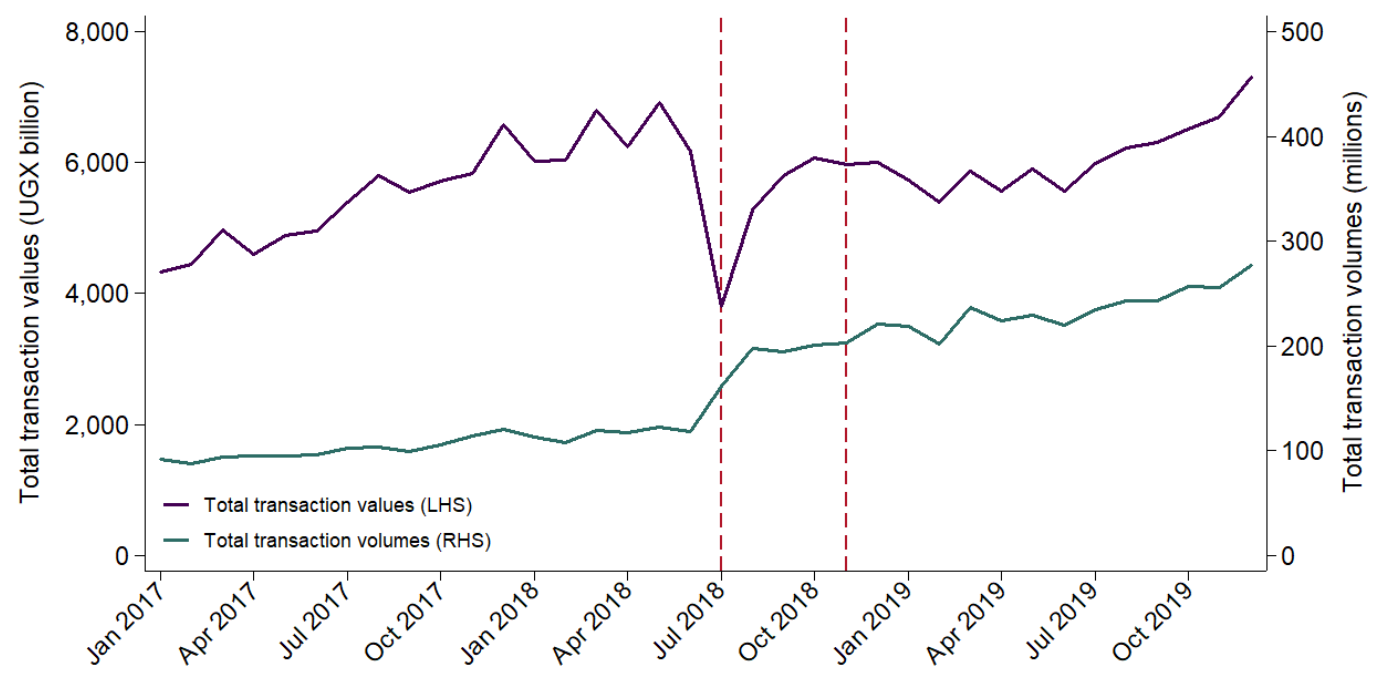

Note: The red indicator lines correspond to the introduction of the tax in July 2018 and the implementation of the subsequent amendment in November 2018. Source: authors' calculations with data from the Bank of Uganda (2021).

Over time, collections from the mobile money tax have somewhat stabilised at a lower level. Figure 3.5 indicates the performance of the tax measure from July 2018 to November 2020. Tax collections (unsurprisingly) declined dramatically when the new tax base and rate was

\footnotetext{
${ }^{23}$ https://twitter.com/mtnug/status/1063702696249761794/photo/1
} 
implemented in November. They continued to decline through to February 2019 before approximately stabilising. In FY 2019/20 the mobile money tax under-performed relative to forecasts, collecting 36 per cent less than in the previous financial year (Uganda Revenue Authority 2020). This could indicate that users of mobile money adjusted their transaction behaviour to avoid the tax applied to mobile money withdrawals. For instance, customers might be avoiding withdrawing by instead using mobile money to pay for goods and services, as suggested by the URA (2020).

Figure 3.5 Revenue performance of the mobile money tax, July 2018 to November 2020

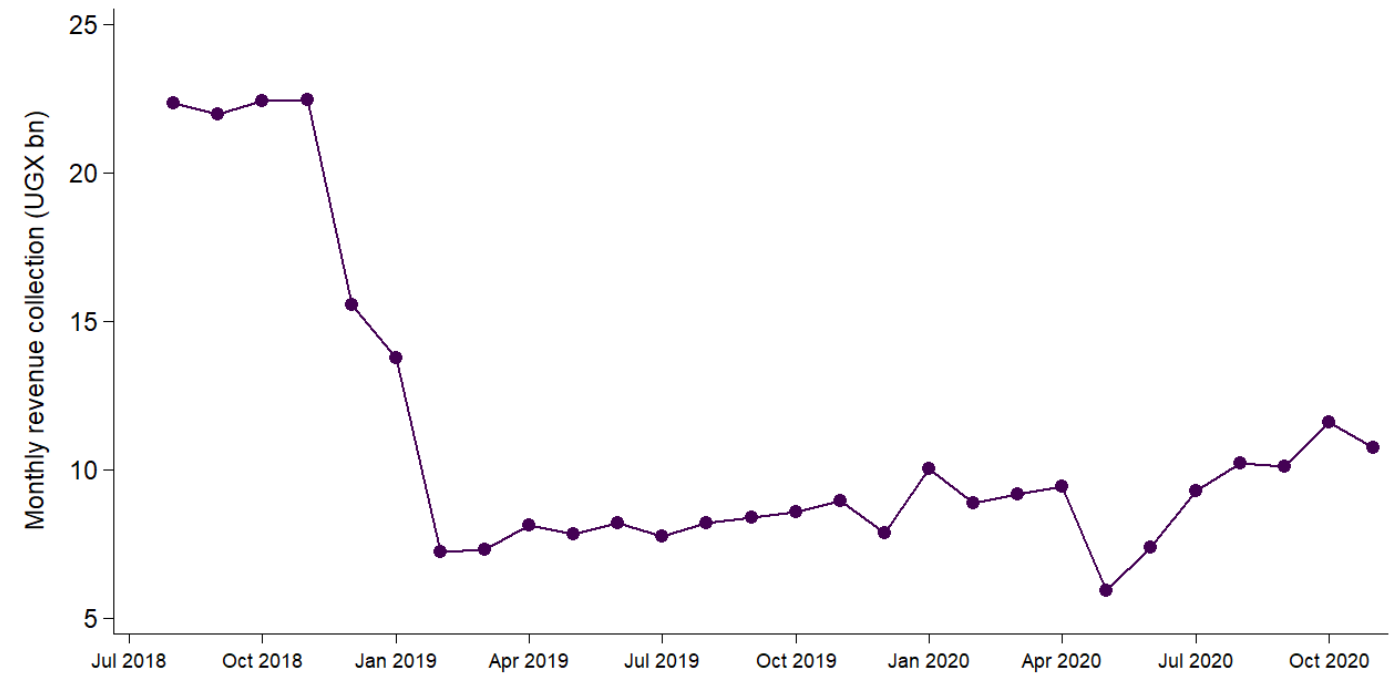

Notes: The marked drop between April and May 2020 corresponds to a very strict lockdown implemented in Uganda to contain the spread of COVID-19. Source: authors' calculations with data supplied by the Tax Policy Department (2021).

\section{Where did the tax policymaking process fail?}

The discussion in section 3 has highlighted that several critical steps in the tax policymaking process were truncated or missed completely, undermining the process. Figure 4.1 gives a summary of the key stages in the development of this measure. One criterion for good policymaking is how well one follows the steps that are set out and generally agreed to, whether formally documented or according to more informal customs. Against this criterion, we see three key problems. 


\section{Figure 4.1 Mobile money tax timeline}

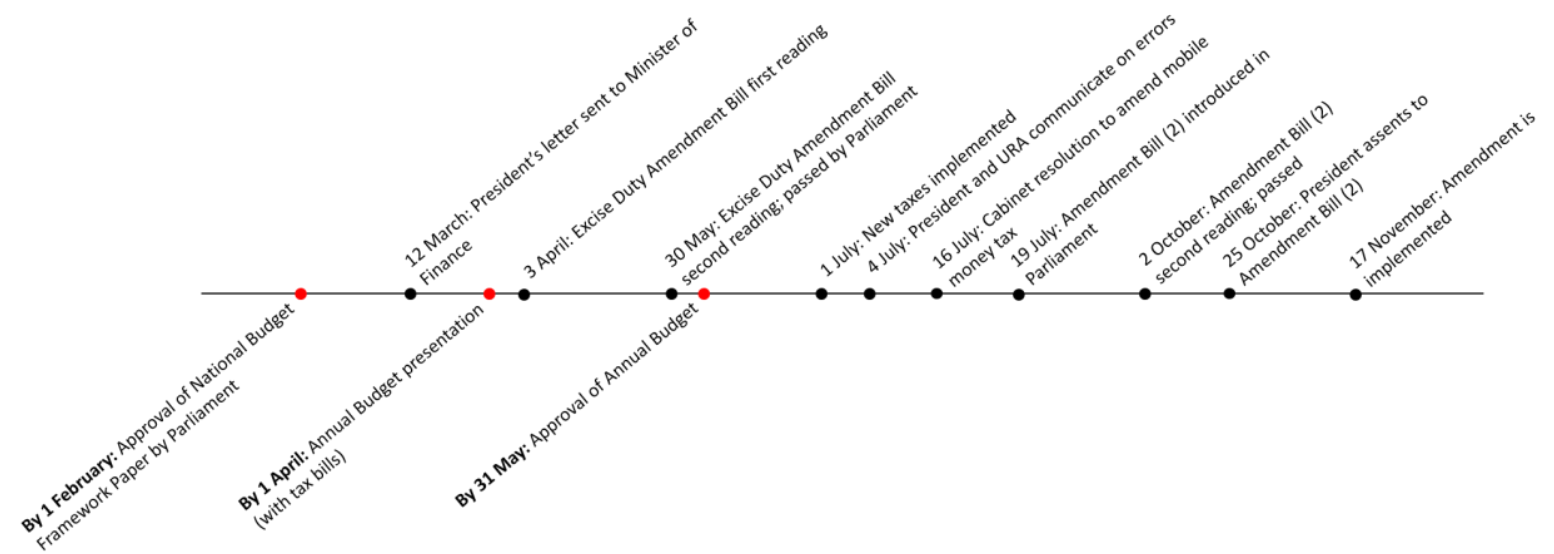

Notes: The descriptions below the line (corresponding to the red dots) refer to deadlines set in the Public Financial Management Act.

Firstly, the policy process was not robust enough to withstand political pressures. In many countries, it is not uncommon for politicians to initiate reforms relatively late in the budget cycle. However, tax policymaking processes should be sufficiently strong and assertive, capable of reacting judiciously to political pressures. In this case, the technical sphere of government appeared to succumb, rushing through an inappropriate measure, without a proper examination of the issue. The development phase, which usually spans a few months, was truncated into about two weeks (see Figure 4.1), undermining the ability of officials to develop viable alternatives. Analytical weaknesses were aggravated by the lack of a welldocumented and widely respected tax policymaking process, introducing scope to bypass due process. If the approach to tax policy development had been more clearly defined, setting out the necessary stages through which policy proposals must pass, this may have helped to ensure that all potential issues were more thoroughly examined.

Secondly, tax policymakers failed to give politicians confidence that their concerns were being addressed. In part, this could be attributed to the lack of a clear medium-term vision for tax policy, which has generally fostered a policymaking environment that is accepting of developing short-term measures to plug budgetary gaps. This can result in tax policy feeling merely reactive to the pressures of the day with no defined objectives of its own. The process of developing a medium-term strategy affords the technical and political sides of government an opportunity to voice their respective concerns and agree on a way forward, while ensuring that technical officials have sufficient time to study proposals. In the case of this tax, the planning phase was almost non-existent, and TPD did not appear to have suitable, convincing alternatives ready. In addition, the tax appeared inconsistent with other GOU strategies. For instance, the National Financial Inclusion Strategy (NFIS), launched in October 2017, paid special attention to the importance of mobile money in expanding access to financial services. This strategy was referenced in the budget papers, but no mention was made about how the new tax might interact with the objectives of the NFIS (Government of Uganda 2018b). There is significant potential to link cross-governmental policy priorities more coherently.

Thirdly, opportunities to properly incorporate stakeholder views and concerns were missed or wasted. While stakeholder consultation in Uganda has room to improve (see Wales and Lees 2020), it was particularly lacking in this case, in large part due to time pressure. Civil society and the private sector were almost entirely excluded during the development phase, despite their obvious skin in the game. Stronger consultations, with the right audience, structured around specific issues, may have contributed to a better understanding of the likely impact of the measure. Such an understanding might have avoided the need for a costly post- 
implementation adjustment. In addition, this might have resolved misconceptions about how mobile money operates, possibly avoiding the initial implementation challenges.

That being said, this tax also presents an unusually successful example of tax bargaining, the process of implicit or explicit negotiation between taxpayers and government. Public, non-institutionalised actors usually have very limited influence on tax policy and do not often constitute a coherent interest group capable of rallying around specific issues (Kangave and Katusiimeh 2015; Kjær and Ulriksen 2014). In response to widespread protest action, the government made an explicit concession to citizens - reducing the tax rate and restricting the base, although the social media tax, which was equally if not more unpopular, was unchanged. There is a vast literature examining the potential for tax bargaining to build citizen-state relationships and improve accountability (for instance, Moore et al. 2018; Moore 2004; Prichard 2010). However, these benefits are typically conditional on the nature of the tax, how the proceeds are spent, and the political and institutional context (Gadenne 2017; Meagher 2018; Moore et al. 2018). It remains to be seen whether this mobilisation of civil society actors around a specific tax issue has strengthened the ability of citizens to demand accountability in the long term. Typically, where actors are restricted to informal, uncoordinated, and reactionary bargaining, their efforts are less sustainable (Kangave and Katusiimeh 2015).

In the wider context of policymaking in Uganda, this is an example of MFPED's declining ability to counter political forces and tightly control the budget process, analysed in detail by Bukenya and Hickey (2019). Public sector management has increasingly been approached as a matter of political expediency, with a clear willingness to compromise the integrity of proper process. Bukenya and Hickey (2019) suggest that this is a symptom of the ruling party's increased vulnerability at elections and a shift in Uganda's political settlement towards more personalised and populist rule by the President. Relatedly, this measure also highlights the declining influence of Uganda's development partners, who were strongly opposed to the tax (see, for instance, the IMF Article IV report (2019) and the World Bank's Uganda Economic Update (2020b)). Donors, especially the World Bank and the IMF, have enjoyed a close relationship with the GOU, with a long history of providing considerable support on revenue policy (Kjær and Ulriksen 2014; Wales and Lees 2020). Several factors have weakened these partnerships, including high-profile corruption scandals triggering the temporary suspension of aid, a shift to more project-based aid rather than budget support, and stronger relationships with partners such as China, who typically have fewer aid conditionalities (Kjær and Ulriksen 2014). Consequently, the GOU have grown more selective in their interaction with donors, and donors have lost some influence over certain facets of the policymaking process.

\section{Policy recommendations}

\subsection{Should the tax be kept, amended further, or repealed?}

While the mobile money tax has raised revenues for the GOU, that is just one criterion by which to evaluate tax policies. Close to three years on from the introduction of the tax, the moment is ripe for a post-implementation review. This would ideally examine the broader economic impact of the tax, the equity implications, who it affects, market responses and distortions, particularly where similar payment mechanisms are not taxed equivalently, and whether it is delivering on its objectives. A review could also consider the efficiency of the mechanisms for collection and the broad structure of the tax. There are various options for doing this work - outsourcing to academia, through a joint effort, or internally. However, without this kind of analysis, one cannot draw holistic conclusions about the effectiveness 
and the success of the measure. Only with this analysis can recommendations for improvement be developed.

\subsection{What does good tax policymaking look like?}

Policymakers, in Uganda and beyond, might be asking what good tax policymaking would look like in similar contexts. From the experience of this tax, we can draw some lessons about how to strengthen the policymaking process in general and insulate it against certain risks. Here, we highlight several components that, when in place and functioning effectively, are likely to produce policy measures that are more nuanced, better understood, more widely accepted, and ultimately more successful.

\subsubsection{Use a medium-term agenda for tax policy}

We have shown that the emphasis on plugging an immediate budget gap contributed to weaknesses in policy development. The development and publication of a medium-term revenue strategy (MTRS) provides an opportunity to establish the direction of travel for tax policy more clearly and rebalance the policy agenda. Publishing a strategy document also serves as an anchor for tax policy, allowing outside stakeholders to interrogate more effectively any deviations from the government's stated plan. This also affords an opportunity to proactively engage with other parts of government to pursue collaborate policy initiatives and ensure that the tax system is aligned with wider policy goals.

\subsubsection{Establish and publicise a robust tax policy process}

A clearly documented, inclusive, and widely respected tax policy formulation process is a powerful defence against interference and short-term thinking. There will inevitably be a degree of eleventh-hour work when developing proposals for the revenue side of the budget. However, the budgetary calendar is predictable, and the same every year. Tax policymakers should aim to schedule the foundational analytical and research work such that the most pressing policy priorities can be delivered early. Establishing a timetable for the revenue side of the annual budget cycle, and documenting this publicly, commits tax policymakers to a standard and systematic approach to all significant policy issues and can make it easier to shelve proposals that are handed down too late in the day. In addition, a publicised timetable allows stakeholders to be more effectively involved, at the right moment and on precisely defined issues.

\subsubsection{Adopt rigorous policy appraisal standards}

As noted earlier, there is considerable scope for improving the quality of the analysis underpinning tax policy proposals. In considering policy options, the focus is often narrowly concentrated on the likely revenue impact. Estimating this accurately, for instance by incorporating evidence-based assumptions about behavioural changes, is important. However, it cannot be the only metric on which to assess proposals. Strong tax policy design typically considers a 'trinity' of criteria: (i) equity or fairness, reflecting on ability-to-pay; (ii) efficiency, ensuring that distortions in economic decision-making are minimised; and (iii) administrability, so that taxes imposed can be collected accurately and at low cost (Bird and Wilkie 2012). These considerations can inform whether a proposal is, on balance, likely to be beneficial or detrimental. Establishing the technical capacity necessary to examine these issues sufficiently should be a priority for tax policy units.

A related concern is that the research and analysis carried out to interrogate policy options is kept secret, and the rationale and evidence in favour of the final proposals are opaque. This damages public trust and confidence in the research done. Publishing more information online for public consumption would not only increase transparency, but also incentivise 
technical officers to produce more rigorous analysis, as the quality and accuracy of their work can be more closely scrutinised.

\subsubsection{Create a two-way bridge between the political and technical spheres}

TPD and URA had not adequately considered messaging from the President in developing their plans. Officials should closely follow the political discourse, as well as anticipate demands to address certain issues and develop responses early. The links between the politicians and the technical departments can be structurally formalised by appointing an advisor to sit between the two. This advisor would ideally be well-versed on fiscal policy and able to provide the technicians with guidance on policy priorities for the politicians. S/he should also be able to help the political sphere, especially ministers in Cabinet, to appreciate complex technical issues and arguments. When combined with a well-run policymaking process, and good resources capable of producing strong analysis, this is a strong mechanism to minimise the disturbance of last-minute political interventions.

\section{Conclusion}

Mobile money is widely believed to be a powerful tool for enhancing financial inclusion and, potentially, improving the economic well-being of the poor. At the same time, cash-strapped governments are increasingly looking for new tax handles to expand their revenue bases. While there is little doubt that governments in many low- and lower-middle-income countries need to increase tax revenues, policymakers should approach the design of tax measures carefully. We have argued that, in the case of the mobile money tax in Uganda, the tax policymaking process failed at several stages, leading to the implementation of an ultimately flawed and unpopular measure. Widespread opposition to the measure followed its implementation, resulting in a period of significant upheaval and confusion. Despite the tax generating revenues in excess of what was predicted at the time, it remains controversial.

Uganda is not alone in its concerns about generating more revenues, effectively taxing the telecommunications sector, and curbing suspected tax evasion in the informal sector. Several other African countries are considering or have experimented with similar taxes on mobile money transactions. We believe that this case study offers valuable lessons in effective tax policymaking. We have highlighted four areas of the process which, when functioning well, can lead to stronger proposals and better outcomes. Firstly, a medium-term policy agenda serves to align the political and technical spheres of government and, by establishing the vision for tax policy, improves predictability. Secondly, establishing and publicising a tax policymaking process reduces the scope for bypassing due process. Thirdly, policy appraisal should be standard and prioritised early on, to understand the full likely impact of proposals. Finally, formalising links between the political and technical spheres of government through the establishment of an advisor can be instrumental in creating broadbased agreement and understanding. 


\section{Appendix}

Table A1 Summary of 2018 Excise Duty Amendment Bill

\begin{tabular}{|c|c|c|}
\hline Category & Amendment type & Tax rate \\
\hline \multicolumn{3}{|l|}{ Telecommunications services } \\
\hline Airtime & $\begin{array}{l}\text { Redefined tax base to draw parity } \\
\text { between mobile cellular, landline, } \\
\text { and public pay phones }\end{array}$ & $12 \%$ of fees charged \\
\hline Over-the-top (OTT) services & New item & $\begin{array}{l}\text { UGX } 200 \text { per user per day } \\
\text { of access }\end{array}$ \\
\hline $\begin{array}{l}\text { Money transfer or withdrawal } \\
\text { services (excluding banks) }\end{array}$ & Increased tax rate & $\begin{array}{l}15 \% \text { of the fees charged } \\
\text { (up from } 10 \% \text { ) }\end{array}$ \\
\hline $\begin{array}{l}\text { Mobile money transactions on } \\
\text { receiving, payments, and } \\
\text { withdrawals }\end{array}$ & New item & $\begin{array}{l}1 \% \text { of the value of the } \\
\text { transaction }\end{array}$ \\
\hline $\begin{array}{l}\text { Incoming international calls, } \\
\text { except from Kenya }\end{array}$ & $\begin{array}{l}\text { Redefined tax base to exclude } \\
\text { Kenya, Rwanda, and South } \\
\text { Sudan }\end{array}$ & US $\$ 0.09$ per minute \\
\hline \multicolumn{3}{|l|}{ Banking } \\
\hline $\begin{array}{l}\text { Ledger fees, ATM fees, } \\
\text { withdrawal fees, and other } \\
\text { transaction and non-transaction } \\
\text { charges charged by financial } \\
\text { institutions }\end{array}$ & Increased tax rate & $\begin{array}{l}15 \% \text { of the fees charged } \\
\text { (up from } 10 \% \text { ) }\end{array}$ \\
\hline \multicolumn{3}{|l|}{ Alcohol } \\
\hline Opaque beer & New item & $\begin{array}{l}30 \% \text { or UGX } 230 \text { per litre, } \\
\text { whichever is higher }\end{array}$ \\
\hline Spirits & $\begin{array}{l}\text { Redefined tax base to distinguish } \\
\text { between undenatured spirits } \\
\text { made from local or imported raw } \\
\text { materials; and ready to drink } \\
\text { spirits }\end{array}$ & $\begin{array}{l}60-100 \% \text { or } \cup G X 1,500 \text { to } \\
2,500 \text { per litre, depending } \\
\text { on the spirit }\end{array}$ \\
\hline Wine & Increased tax rate & $\begin{array}{l}20 \% \text { or UGX } 2,000 \text { per litre } \\
\text { for wine produced from } \\
\text { local raw materials; } 80 \% \text { or } \\
\text { UGX } 8,000 \text { per litre } \\
\text { otherwise }\end{array}$ \\
\hline \multicolumn{3}{|r|}{ 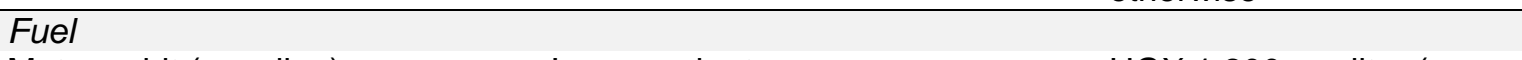 } \\
\hline Motor spirit (gasoline) & Increased rate & $\begin{array}{l}\text { UGX } 1,200 \text { per litre (up } \\
\text { from UGX } 1,100 \text { ) }\end{array}$ \\
\hline $\begin{array}{l}\text { Gas oil (automotive, light, amber } \\
\text { for high-speed engine) }\end{array}$ & Increased rate & $\begin{array}{l}\text { UGX } 880 \text { per litre (up from } \\
\text { UGX } 780 \text { per litre) }\end{array}$ \\
\hline \multicolumn{3}{|l|}{ Other items } \\
\hline Cooking oil & New item & UGX 200 per litre \\
\hline Motorcycles, at first registration & New item & UGX 200,000 \\
\hline $\begin{array}{l}\text { Powder for reconstitution to } \\
\text { make juice }\end{array}$ & New item & $15 \%$ of the value \\
\hline
\end{tabular}


Figure A1 Abbreviated structure of the Ministry of Finance, Planning and Economic Development

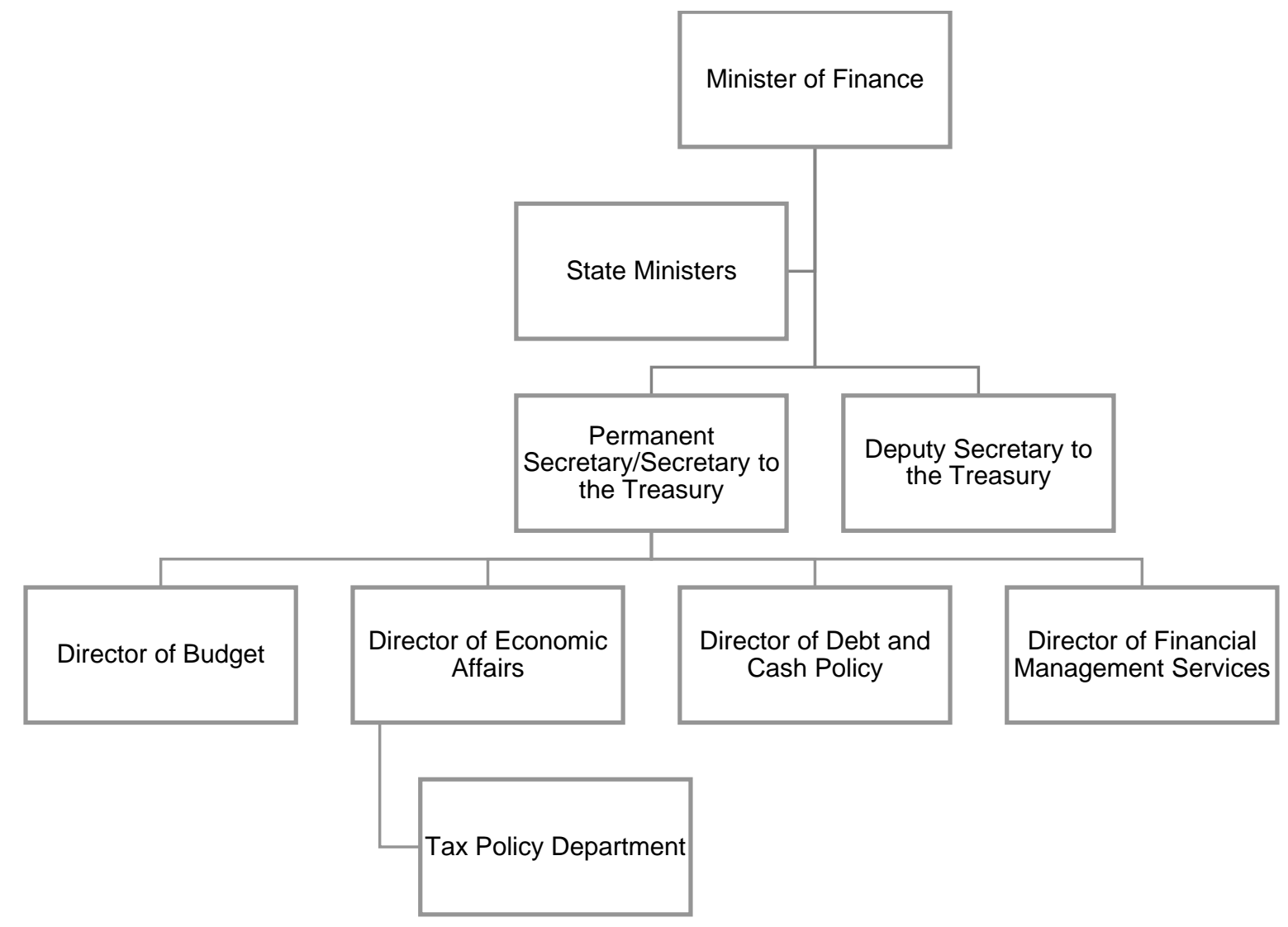




\section{References}

Adegoke, Y. (2018) 'Ugandans are Furious with a New Tax for Using Social Media and Mobile Money', Quartz Africa, 1 July, https://qz.com/africa/1319064/uganda-socialmedia-and-mobile-money-tax-now-in-effect/

Arnold, B. J. (2013) 'The Process of Making Tax Policy: An International Comparison', Canadian Tax Journal 61.4: 989-1009

Aron, J. (2018) 'Leapfrogging: A Survey of the Nature and Economic Implications of Mobile Money', The World Bank Research Observer 33.2

Bank of Uganda (2021) Mobile Money Statistics, Kampala: Bank of Uganda, www.bou.or.ug/bou/bouwebsite/PaymentSystems/dataandstat.html

(2017) National Financial Inclusion Strategy 2017-2022, Kampala: Bank of Uganda, www.bou.or.ug/bou/bouwebsite/bouwebsitecontent/publications/special_pubs/2017/Nat ional-Financial-Inclusion-Strategy.pdf

Bateman, M., Duvendack, M. and Loubere, N. (2019) 'Is Fintech the New Panacea for Poverty Alleviation and Local Development? Contesting Suri and Jack's M-Pesa Findings Published in Science', Review of African Political Economy 46.161: 480-495

Bird, R. and Wilkie, J. S. (2012) Designing Tax Policy: Constraints and Objectives in an Open Economy, International Center for Public Policy Working Paper 12-24, Atlanta: International Center for Public Policy, Andrew Young School of Policy Studies, Georgia State University

Boxell, L. and Steinert-Threlkeld, Z. (2019) 'Taxing Dissent: The Impact of a Social Media Tax in Uganda', arXiv preprint arXiv:1909.04107

Bukenya, B. and Hickey, S. (2019) The Shifting Fortunes of the Economic Technocracy in Uganda: Caught Between State-building and Regime Survival? ESID Working Paper 121, Manchester, UK: Effective States and Inclusive Development Centre

Civil Society Budget Advocacy Group (CSBAG) (2018) 8 Reasons Why Taxing Transaction Value on Mobile Money is a Bad Idea, Kampala: CSBAG, www.csbag.org/download/8reasons-why-taxing-transaction-value-on-mobile-money-is-a-badidea/?wpdmdl=1717\& refresh $=5$ f7de393574241602085779

Clifford, K. (2020) The Causes and Consequences of Mobile Money Taxation: An Examination of Mobile Money Transaction Taxes in Sub-Saharan Africa, London: GSMA

Cottarelli, C. (2012) 'Structures, Processes and Governance in Tax Policy-making', speech, Oxford, 8 March 2012, www.imf.org/en/News/Articles/2015/09/28/04/53/sp030812

Daily Monitor (2018a) 'Yoweri Museveni Slaps Taxes on Social Media Users in Uganda', The East African, 2 April, www.theeastafrican.co.ke/tea/news/east-africa/yoweri-musevenislaps-taxes-on-social-media-users-in-uganda-1387344

(2018b) 'Uganda Nets \$1.8 Million from Social Media, Mobile Money Tax', The East African, 18 July, www.theeastafrican.co.ke/tea/business/uganda-nets-1-8-million-fromsocial-media-mobile-money-tax-1398482 
Demirgüç-Kunt, A., Klapper, L., Singer, D., Ansar, S. and Hess, J. (2018) The Global Findex Database 2017: Measuring Financial Inclusion and the Fintech Revolution, Washington, DC: World Bank Group

Duvendack, M. and Mader, P. (2020) 'Impact of Financial Inclusion in Low- and MiddleIncome Countries: A Systematic Review of Reviews', Journal of Economic Surveys 34.3: $594-629$

Financial Sector Deepening Uganda (FSDU) (2018) FinScope Uganda: Topline Findings Report, Kampala: FSDU

Fuchs, M., Musuku, T. B. and Symington, D. (2017) Mobile Money Taxation: Policy Issues and Considerations for Pakistan and Tanzania, Washington, DC: World Bank Group and Oxford Policy Management

Gadenne, L. (2017) 'Tax Me, But Spend Wisely: The Political Economy of Taxes, Evidence from Brazilian Local Governments', American Economic Journal: Applied Economics 9.1: 274-314

Google Trends (2021) Mobile Money Tax, https://trends.google.com/trends/explore?date=2018-01-01\%202018-12$31 \&$ geo=UG\&q=mobile\%20money\%20tax

Gordon, R. K. and Thuronyi, V. (2012) 'Tax Legislative Process', revision of 'Tax Law Design and Drafting' (1996), Washington, DC: International Monetary Fund, www.imf.org/external/pubs/nft/1998/tlaw/eng/ch1.pdf

Government of Uganda (2020) Domestic Revenue Mobilisation Strategy FY2019/20 FY2023/24, Kampala: Ministry of Finance, Planning and Economic Development

(2018a) The Excise Duty (Amendment) Act 2018, www.parliament.go.ug/documents/3344/acts-2018

(2018b) Background to the Budget Fiscal Year 2018-19,

www.finance.go.ug/publication/background-budget-fiscal-year-2018-2019

Gneezy, U. and Imas, A. (2017) 'Lab in the Field: Measuring Preferences in the Wild', Handbook of Economic Field Experiments 1: 439-464

Grote, M. (2017) Fiscal Policy: How to Establish a Tax Policy Unit, Washington, DC: Fiscal Affairs Department, International Monetary Fund

ICTD/UNU-WIDER (2020) Government Revenue Dataset, www.wider.unu.edu/project/government-revenue-dataset

International Monetary Fund (IMF) (2019) Uganda: 2019 Article IV Consultation Staff Report, Country Report No. 19/125, Washington, DC: IMF

The Independent (2018) 'THIS WEEK: Museveni Proposes Tax on WhatsApp, Facebook', 7 April, www.independent.co.ug/this-week-museveni-proposes-tax-on-whatsappfacebook/

(2016) 'BUDGET: Museveni Warns Telecoms on Tax Evasion', 9 June, www.independent.co.ug/budget-museveni-warns-telecoms-on-tax-evasion/ 
Jack, W. and Suri, T. (2016) 'The Long-Run Poverty and Gender Impacts of Mobile Money', Science 354.6317: 1288-1292

- and Suri, T. (2014) 'Risk Sharing and Transaction Costs: Evidence from Kenya's Mobile Money Revolution', American Economic Review 104.1: 183-223

Ray, A. and Suri, T. (2013) 'Money Management by Households and Firms in Kenya', American Economic Review: Papers and Proceedings 103.3: 1-8

Kangave, J. and Katusiimeh, M. W. (2015) Tax Bargains: Understanding the Role Played by Public and Private Actors in Influencing Tax Policy Reform in Uganda, UNRISD Working Paper 2015-2, United Nations Research Institute for Social Development

Kjær, A. M. and Ulriksen, M. S. (2014) From Consensus to Contention: Changing Revenue and Policy Dynamics in Uganda, UNRISD Working Paper 2014-21, United Nations Research Institute for Social Development

Langford, B. and Ohlenburg, T. (2016) Tax Revenue Potential and Effort: An Empirical Investigation, S-43202-UGA-1, International Growth Centre Working Paper, London: International Growth Centre

Matheson, T. and Petit, P. (2017) Taxing Telecommunications in Developing Countries, IMF Working Paper 17/247, Washington, DC: International Monetary Fund

Meagher, K. (2018) 'Taxing Times: Taxation, Divided Societies and the Informal Economy in Northern Nigeria', The Journal of Development Studies 54.1: 1-17

Moore, M. (2020) What is Wrong with African Tax Administration? ICTD Working Paper 111, Brighton: Institute of Development Studies

(2004) 'Revenues, State Formation and the Quality of Governance in Developing

Countries', International Political Science Review 25.3: 297-319

Prichard, W. and Fjeldstad, O.-H. (2018) Taxing Africa: Coercion, Reform and

Development, London: Zed Books

Fjeldstad, O.-H., Isaksen, J., LundstøI, O., McCluskey, R. and Prichard, W. (2015)

Building Tax Capacity in Developing Countries, IDS Policy Briefing 96, Brighton: Institute of Development Studies

Munyegera, G. K. and Matsumoto, T. (2016) 'Mobile Money, Remittances, and Rural Household Welfare: Panel Evidence from Uganda', World Development 79.C: 127-137

Museveni, Y. (2018a) 'Why the Government is Taxing Social Media', blog,

www.yowerikmuseveni.com/why-government-taxing-social-media-president-museveni

- (2018b) 'President Responds to Feedback to Earlier Statement on the New Social Media and Mobile Money Taxes', blog,

www.yowerikmuseveni.com/blog/museveni/president-responds-feed-back-earlierstatement-new-social-media-and-mobile-money-taxes

National Information Technology Authority Uganda (NITA-U) (2018) National Information Technology Survey: 2017/18 Report 
New Vision (2018) 'Parliament Set to Decide Fate of Mobile Money Tax', 2 October, www.newvision.co.ug/news/1486780/parliament-set-decide-fate-mobile-money-tax

Ndung'u, N. S. (2019) Taxing Mobile Phone Transactions: Lessons from Kenya, Africa Growth Initiative Policy Brief, Washington, DC: Brookings Institute

The Observer (2018) 'Telecoms, Bank of Uganda Want Mobile Money Tax Scrapped', 2 August, https://observer.ug/news/headlines/58334-telecoms-bank-of-uganda-wantmobile-money-tax-scrapped.html

Parliament of Uganda (2018a) The Excise Duty (Amendment) Bill, 2018, www.parliament.go.ug/documents/3124/bills-2018

(2018b) Report of the Committee on Finance, Planning and Economic Development on The Excise Duty (Amendment) Bill, 2018, https://parliamentwatch.ug/wpcontent/uploads/2018/05/FPED3-18-Report-on-the-Excise-Duty-Amendment-Bill2018.pdf

(2018c) Parliament Hansard - 30 May 2018, www.parliament.go.ug/documents/2034/hansards-2018-may

(2018d) 'Government Should Expedite Review of Mobile Money and Social Media Tax - Kadaga', 12 July, www.parliament.go.ug/news/2061/gov\%E2\%80\%99t-shouldexpedite-review-mobile-money-social-media-tax-\%E2\%80\%93-kadaga

Prichard, W. (2010) Taxation and State Building: Towards a Governance Focused Tax Reform Agenda, IDS Working Paper 341, Brighton: Institute of Development Studies

Reuters (2018a) 'Uganda Police Use Teargas to Disperse Protest Against Social Media Taxes', 11 July, www.reuters.com/article/us-uganda-socialmedia-protestsidUSKBN1K121S

(2018b) 'Uganda Telecom Operators to Start Charging Social Media Tax', 29 June, www.reuters.com/article/uganda-telecoms/uganda-telecom-operators-to-start-chargingsocial-media-tax-idUSL8N1TV3TZ

Riley, E. (2018) 'Mobile Money and Risk Sharing Against Village Shocks', Journal of Development Economics 135: 43-58

Suri, T. (2017) 'Mobile Money', Annual Review of Economics 9: 497-520

Tax Working Group (TWG) (2018) The Generic Tax Policy Process, Position Paper for Session 14 of the Tax Working Group, Auckland: Inland Revenue Department and the Treasury

Uganda Bureau of Statistics (UBOS) (2020) Annual GDP Publication Tables Revised, www.ubos.org/explore-statistics/9/

United Nations Capital Development Fund (UNCDF) (2018) 'Understanding the Consequences of Mobile Money Taxes in Uganda', 29 August, www.uncdf.org/article/3892/understanding-the-consequences-of-mobile-money-taxesin-uganda 
Uganda Revenue Authority (2020) Revenue Performance Report FY 2019/20, www.ura.go.ug/openFile.do?path=//webupload//upload//download//staticContent//TOP MENU//9907//10192_RPR.pdf

(2019) Revenue Performance Report FY 2018/19, www.ura.go.ug/Resources/webuploads/GNRART/Annual\%20Revenue\%20Report\%20 FY\%202018-19.pdf

(2018) Revenue Performance Report FY 2017/18, www.ura.go.ug/Resources/webuploads/GNRART/Annual\%20Revenue\%20Report_201 7_18.pdf

Wales, C. and Lees, A. (2020) Report on the Tax Policymaking Process in Uganda, London: Overseas Development Institute

and Wales, C. (2012) Structures, Processes and Governance in Tax Policy Making, Oxford: Oxford University, Centre for Business Taxation

Wamala, M. (2018) 'Mobile Money Tax Was Passed in Error - Kasaija', New Vision, www.newvision.co.ug/news/1479138/mobile-money-tax-passed-error-kasaija

Wesonga, N. and Kyeyune, M. (2018) 'Uganda: Mobile Money Usage Drops by Shs672 Billion in Two Weeks', AllAfrica, 2 August, https://allafrica.com/stories/201808020096.html

Whitehead, A. (2019) Uganda Social Media and Mobile Money Taxes Survey Report, Whitehead Communications Report.

World Bank (2020a) DataBank: World Development Indicators, https://databank.worldbank.org/source/world-development-indicators (2020b) Uganda Economic Update, 15 th Edition: Digital Solutions in a Time of Crisis, Washington, DC: World Bank Group

(2018) Uganda Economic Update, 11 th Edition: Financing Growth and DevelopmentOptions for Raising More Domestic Revenue, Washington, DC: World Bank Group 